\title{
LIBERTAD DE EXPRESIÓN Y TUTELA DE LA CORONA: EL CASO DE «EL JUEVES»
}

\author{
IGNACIO FERNÁNDEZ SARASOLA \\ Profesor Titular de Derecho Constitucional \\ Universidad de Oviedo
}

\section{SUMARIO}

I. Breve introducción. II. «El Jueves», una publicación incómoda. III. Los excesivos límites legislativos al mundo gráfico. IV. Error de juicio. V. La «insumisión» de «El Jueves». VI. Daños colaterales.

\section{BREVE INTRODUCCIÓN}

Acaban de cumplirse diez años de un aniversario — si es que esta palabra puede aplicarse aquí- poco gratificante para la libertad de prensa: el secuestro judicial de la revista satírica «El Jueves», y la posterior condena penal a los autores de su portada por un delito contra el honor de la Corona.

El suceso en sí marcó una pauta. Como pretendo mostrar en las páginas siguientes, se trató de una actuación judicial desmedida y de dudosa constitucionalidad que, al menos momentáneamente, tuvo unas consecuencias poco gratificantes: la propia revista optó en números sucesivos por la autocensura. Por fortuna, el dislate del caso fue tal que en los años sucesivos el panorama volvió a recomponerse. Las justificadas críticas que le llovieron a la Audiencia Nacional por su resolución espolearon a las publicaciones a mantener su anterior línea de ironizar sin miedo a procesos judiciales, en tanto la judicatura parece haber optado por ser más rigurosa a la hora de aplicar tipos penales que limiten el ejercicio del derecho fundamental a la libertad de expresión.

El sobreseimiento de los encausados en el llamado «caso de los titiriteros» ${ }^{1}$, o la sentencia de la Audiencia Nacional absolviendo al promotor de una sonora pitada contra el Jefe del Estado y el himno de España en la final de la Copa del

1 Un detallado análisis del suceso y su repercusión mediática puede consultarse en M.E. GuTiÉrREZ, «Cuando la sátira se convierte en expresión ofensiva. Reflexión en torno al «Caso de los Titiriteros», Tebeosfera, n. ${ }^{\circ}$, 2016, pp. 1-14. 
Rey que tuvo lugar hace unos años son ejemplos que ponen de manifiesto una recuperación de la integridad constitucional de la libertad de expresión o, lo que es lo mismo, una mayor proporcionalidad a la hora de limitar tal derecho.

Pero esta situación de bonanza no debe promover a un optimismo desmedido. En un momento en el que lo «políticamente correcto» cotiza al alza, se aprecian actitudes que fácilmente pueden transitar de la censura social a la represión judicial. Y, lo que es peor, puede traer consigo una vez más situaciones de autocensura. Conviene, pues, recordar aquel caso lamentablemente judicializado, para que nos recuerde cuán fácil es poner a la libertad de expresión contra las cuerdas.

\section{II. «EL JUEVES», UNA PUBLICACIÓN INCÓMODA}

La revista «El Jueves» es cronológicamente hija de la Transición política, y temáticamente bisnieta de publicaciones satíricas de la talla de «Cu-Cut» o «La Codorniz». Diseñada, no obstante, con una vocación más costumbrista que las anteriores $^{2}$, su humor irreverente atrajo las iras de propios y extraños. Si la sede de «Cu-Cut» sufrió un atentado en 1905 protagonizado por un grupo de soldados que irrumpieron en los talleres de la publicación, causando cuantiosos destrozos e hiriendo a varios transeúntes ${ }^{3}$, los responsables de «El Jueves» también vivieron la intransigencia en sus carnes. Sufrió por igual amenazas de bomba, airadas llamadas de atención de personajes públicos y, cómo no, algunas demandas de quienes se sentían agraviados por sus chanzas.

Los principales conflictos de «El Jueves» lo enfrentaron con la iglesia católica, que con harta frecuencia se consideró ofendida por la revista satírica. Y en la contienda, la publicación no siempre salió bien parada: en 1977 sufrió el secuestro administrativo de su número séptimo, cuya portada rezaba «Lefebvre se cisma en el Papa», en referencia a la rotura con la Iglesia Católica del obispo francés M. Lefébvre, renuente a aceptar las reformas aperturistas del Concilio Vaticano II. El número 44 (25 de mayo de 1978) fue por su parte objeto de un proceso judicial por un presunto delito de escarnio contra la religión (art. 209 del Código Penal) derivado de un chiste gráfico y del que, en este caso, la publicación resultó finalmente absuelta (STS 67/1983, de 5 de enero). Sin embargo, un año más tarde, uno de los colaboradores habituales de «El Jueves», J.L. Martín Zabala, fue condenado por escarnio contra la religión por su obra «La Biblia contada a los pasotas»; un volumen en el que utilizaba al personaje de Dios, popularizado en aquella

2 M. Barrero, «El Jueves: revista de la Transición, revista en transición», Tebeosfera, n. ${ }^{\circ}$ 12, 2014.

3 Meléndez Malavé, N., «La libertad de expresión más allá de los límites de la viñeta: de Charles

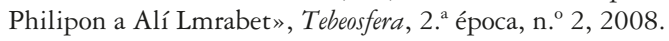


revista y que ya le había supuesto varios procesos de los que había sido hasta entonces absuelto.

Más permisivas fueron siempre las autoridades públicas, que soportaron con entereza el corrosivo e ingenioso humor de los caricaturistas de «El Jueves». Desde la portada del número 174 (24-30 de septiembre de 1980), representando a A. Suárez como una prostituta, pasando por los chistes con explícitas connotaciones sexuales con protagonistas tanto del Ejecutivo nacional (Aznar, Zapatero...) como de otros países (Condolezza Rice, George Bush y, por supuesto, Bill Clinton...), «El Jueves» no tuvo reparos en convertir a los gobernantes en blanco de sus mofas. Tampoco se salvó la justicia, a la que en las portadas se la calificaba como torpe, lenta, loca y un mero «show», o se la representaba con su figura alegórica siendo manoseada por M. Conde o sodomizada por A. Pinochet.

Obviamente tampoco la Corona iba a quedar al margen de las irreverentes burlas de «El Jueves». Bien es cierto que en las primeras portadas se aprecia una mal disimulada autocontención respecto a los Monarcas, al punto de que apenas se percibe crítica alguna a la institución. No obstante, la situación comenzó a cambiar sensiblemente hacia el año 1990, fecha en la que empezaron a proliferar chistes algo más incisivos que tenían por protagonista al entonces Príncipe de Asturias, convertido por obra de «El Jueves» en un impenitente casadero al que sus progenitores intentaban desesperadamente emparentar ${ }^{4}$. Tampoco faltaron referencias a la endémica tendencia del Rey a lesionarse practicando esquí, aunque los chistes tenían un tono más que comedido5. La boda del Príncipe supuso un escalón más en la mordacidad de las sátiras, sobre todo por el creciente tono sexual de los dibujos: levantándole la falda a la princesa Letizia en la boda real, exhibiéndola en «top less» durante las vacaciones (aunque todavía de espaldas), o refiriéndose al interés institucional porque se quedase embarazada, con alguna que otra referencia a populares programas televisivos de aquel entonces dedicados a la sexología.

Con el tiempo, la ridiculización de los miembros de la Familia Real fue ganando más y más intensidad... hasta alcanzar su cenit en 2007. Aquel año, el Presidente del Gobierno, J.L. Rodríguez Zapatero, había anunciado una ayuda de dos mil quinientos euros por cada hijo nacido en España, con el objetivo de incentivar la natalidad en nuestro país, lastrado con una curva demográfica decreciente. «El Jueves» aprovechó la noticia para retratar al Príncipe Felipe manteniendo relaciones sexuales con su esposa mientras decía « ¿Te das cuenta? Si te quedas preñada... ¡Esto va a ser lo más parecido a trabajar que he hecho en mi vida!» (n. ${ }^{\circ} 1573,18$ de julio de 2007). En el texto no figuraba por ningún lado el nombre de los susodichos miembros de la Familia Real, aunque de las espléndidas caricaturas se deducía fácilmente que se trataba de ellos.

4 Véase por ejemplo las portadas de los núms. 681 (13-19 de junio de 1990), 744 (28 de agosto - 3 de septiembre de 1991), 779 (29 de abril — 5 de mayo de 1992).

5 Por ejemplo los núms. 764 (15-21 de enero de 1992) y 815 (6-12 de enero de 1993). 
A instancias de la Fiscalía General del Estado, el juez de la Audiencia Nacional J. del Olmo ordenó el secuestro del número, así como decomisar el molde del dibujo y cerrar la edición digital, entendiendo que la portada incurría en una extralimitación del ejercicio de la libertad de expresión. El susodicho Fiscal General del Estado, C. Conde Pumpido, promotor del secuestro de la publicación, había calificado la sátira de innecesaria para el mensaje que querían transmitir, afirmando que incurría claramente en un hecho delictivo ${ }^{6}$. Una opinión en la que no coincidió, dicho sea de paso, la mayoría de los juristas consultados por la prensa nacional ${ }^{7}$. En todo caso, el Fiscal General del Estado solicitó que se identificase a los autores de la caricatura y se les incoase un proceso penal. Dicho y hecho. En noviembre de 2007, los dibujantes G. Torres y M. Fontdevila se vieron las caras ante el Juzgado Central de lo Penal de la Audiencia Nacional, en un proceso en el que el juez J.M. Vázquez Honrubia los halló culpables de un delito de injurias a la Corona, tipificado en los artículos 491.1 y 491.2 del Código Penal, condenándolos a una multa de tres mil euros ${ }^{8}$. Malos tiempos para la lírica.

\section{LOS EXCESIVOS LÍMITES LEGISLATIVOS AL MUNDO GRÁFICO}

El único punto en el que tanto el auto del Juez del Olmo como la sentencia del juez J.M. Vázquez Honrubia parecen haber acertado reside en la consideración de que ningún derecho fundamental es ilimitado. En efecto, como los restantes derechos constitucionales, también la libertad de expresión y el derecho de creación artística y literaria se hallan sujetos a límites, ya sean estos internos (es decir, previstos en la propia Constitución) o externos (incorporados por el legislador). Entre los primeros, la propia norma fundamental (art. 20.4) destaca que las citadas libertades de expresión y creación artística y literaria están limitadas por el respeto al honor, intimidad y propia imagen (límites internos positivos); un inciso que resulta por otra parte innecesario, ya que podría deducirse de la presencia de esos derechos en el artículo 18 de la norma magna (lo cual los convierte

6 «Conde Pumpido asegura que la portada de 'El Jueves' es delictiva», El País (21-07-2007).

7 En concreto, en el diario «El País» expresaron su opinión cuatro catedráticos de Derecho Constitucional, de los cuales, tres se pronunciaron en contra de una medida como el secuestro, al considerarlo desproporcionado (E. Vírgala Foruria y A. SAIz ARnÁIz) y la crítica de «El Jueves» como ejercicio legítimo de la libertad de expresión (G. RuIz Rico). Apenas el profesor J.J. SolozÁbal Echevarría consideró la intervención adecuada. «Expertos constitucionalistas discrepan sobre la legalidad de la sátira hacia la familia real», El País (21-07-2007). En «El Periódico», uno de los mayores expertos de nuestro país en la libertad de expresión, el profesor M. Carrillo, sostuvo en un amplio artículo la falta de proporcionalidad de la medida adoptada por el juez del Olmo. M. Carrillo, «Las cortapisas al ejercicio de un derecho constitucional. Sátira y libertad de expresión», El Periódico (31-07-2007).

8 Para un análisis detallado de las circunstancias que rodearon al proceso, de otros antecedentes, y una visión crítica de la sentencia, me remito al detallado trabajo de F. RAMOS, «El secuestro de El Jueves y las injurias periodísticas a la corona, un injustificable ataque a la libertad de expresión», Ámbitos, n. ${ }^{\circ}$ 16, 2007, pp. 151-186. 
en un límite interno lógico o inmanente). De todas estas restricciones, la relevante para el caso que nos ocupa es el respeto al derecho al honor.

Pues bien, la presencia de este límite reviste matices cuando la persona que se considera injuriada es titular de un órgano público, lo cual conduce a varios interrogantes: ¿los poderes públicos son, en sí mismos, titulares del derecho al honor? Y, segunda cuestión: quien está al frente de un órgano estatal, ¿puede esgrimir el derecho al honor con la misma extensión que lo haría un particular, ajeno a la vida pública?

Respecto al primer asunto, el Tribunal Constitucional ha dejado claro que la titularidad del derecho al honor no sólo corresponde a las personas físicas, sino también a las jurídicas (STC 139/1995, de 26 de septiembre, FJ 5. .). Pero, ¿y si esas personas jurídicas son, además, poderes públicos? Pues bien, con carácter general debe apuntarse que la jurisprudencia del Tribunal Constitucional ha optado principalmente por una dogmática liberal de los derechos, concibiéndolos como libertades frente al Estado, con lo cual ha tendido a negar que los poderes públicos puedan ser titulares de derechos. Aun así, el alto Tribunal les ha reconocido la titularidad de ciertos derechos conectados con el ejercicio de sus funciones, como el de tutela judicial efectiva (STC 64/1988, FJ 1. ${ }^{\circ}$ ) y el de información (STC 190/1996, FJ 3..). No parece descabellado extender a los poderes públicos la titularidad de otros derechos que por su naturaleza estén en condiciones de ejercer ${ }^{9}$, entre los que podría situarse el derecho al honor.

Esta es, en realidad, la idea que subyace al Código Penal, por cuanto tipifica como injurias el menoscabo de las Cortes o de las Asambleas Autonómicas (art. 496), del Gobierno, del Consejo General del Poder Judicial, del Tribunal Constitucional, del Tribunal Supremo, del Consejo de Gobierno autonómico o del Tribunal Superior de Justicia de una Comunidad Autónoma (art. 504), así como del Rey, su consorte, ascendientes, descendientes o príncipe heredero, y al regente o miembro de la Regencia (arts. 490-491). Si el honor está descrito —en términos jurídicos - como «la buena reputación de una persona, protegiéndola frente a expresiones o mensajes que puedan hacerla desmerecer en la consideración ajena al ir en su descrédito o menosprecio o al ser tenidas en el concepto público por afrentosas» (STC 49/2001, FJ 5.º), parece claro que los órganos públicos también gozan de un crédito que puede ser digno de tutela respecto de expresiones injuriosas.

Aclarado este extremo, es preciso, sin embargo, determinar si los órganos públicos poseen un derecho al honor equiparable al de los ciudadanos. Para responder a este interrogante conviene recordar que el propio Tribunal Constitucional ha señalado que los ciudadanos, en el ejercicio de sus derechos del artículo 20 , disponen una facultad de «libre crítica de la actuación de las instituciones

9 B. Aláez Corral, «Los sujetos de los derechos fundamentales», F. Bastida y otros, Teoría General de los derechos fundamentales en la Constitución española de 1978, Tecnos, Madrid, 2004, p. 90. 
representativas» (STC 185/1989, FJ 4..$^{\circ}$ ). Obviamente, la formación de una opinión pública libre en un sistema democrático habilita a que los ciudadanos puedan criticar abiertamente el funcionamiento de los órganos públicos, su propia existencia (avalada por la posibilidad de su supresión mediante reforma constitucional o legislativa) o la actuación de quienes están al frente de los mismos (STC 148/2001, FJ. $\left.6^{\circ}\right)^{10}$. A esta capacidad de crítica se une la idea plasmada por el propio Tribunal de que la libertad de expresión ostenta, respecto del derecho al honor, una posición de prevalencia, por tratarse de un derecho con una doble dimensión (libertad individual y garantía de opinión pública, ligada esta última al pluralismo político), lo cual obliga a que los límites a la libertad de expresión derivados de su hipotética colisión con el honor hayan de interpretarse de forma restrictiva (STC 42/1995, FJ 2. ${ }^{\circ}$ y STC 85/1992, FJ 4. $\left.{ }^{\circ}\right)^{11}$. En realidad, esto es también lo que fija la propia legislación española al reconocer que no existe vulneración del derecho al honor cuando se elaboran caricaturas de personas que ejerzan un cargo público o una profesión con notoriedad o proyección pública ${ }^{12}$, así como cuando el Código Penal prevé que sólo se incurrirá en delito de injurias en el caso de que, en atención a la naturaleza, efectos y circunstancias de los hechos, pueda reputarse una lesión grave del honor ${ }^{13}$.

Así las cosas, parece razonable considerar que, aunque los órganos públicos y quienes los ejercen son titulares de un derecho al honor (equivalente al prestigio de la institución que resulta preciso para su funcionamiento), éste resulta más susceptible de restricción, debido al derecho de crítica que los ciudadanos deben estar en condiciones de ejercer en un sistema democrático. Dicho en otros términos: si en el caso de las relaciones entre particulares (eficacia horizontal) la libertad de expresión debe tener en cuenta el derecho al honor (ya que se trata de sujetos sin relevancia pública), en el caso de un órgano público la situación se invierte, de modo que es el derecho al honor de dicho órgano el que debe tener presente la libertad de expresión, al punto que aquél no puede esgrimirse más que en los casos de injurias graves.

Pero, a pesar de esta regla general, nuestro ordenamiento jurídico introduce algunos inexplicables matices en el caso de la Corona. En primer lugar, porque utiliza un concepto amplio de este órgano, confiriéndole protección no sólo a su titular (el Rey), sino también a su consorte, ascendientes, descendientes ${ }^{14}$ y prín-

10 Véase también las SSTC 6/1981, 12/1982 o 159/1986.

11 Y ello a pesar de que la idea de que un derecho «prevalezca» sobre otro resulta en sí misma discutible. Siendo todos los derechos fundamentales, por igual, norma jurídica suprema, no puede admitirse esa prevalencia de los unos sobre los otros. Antes bien, la presencia de todos ellos lo que hace es constreñir los unos sobre los otros, introduciendo límites lógicos.

12 Art. 8 de la L.O. 1/1982, de 5 de mayo, de protección civil del derecho al honor, a la intimidad personal y familiar y a la propia imagen.

13 Art. 208 de la L.O. 10/1995, de 23 de noviembre, del Código Penal.

14 Conviene recordar que en el proyecto de la L.O. 10/1995, del Código Penal, esta referencia a los «ascendientes y descendientes» del Rey no se hallaba (antiguo artículo 469.3), de modo que sólo se castigaban las injurias y calumnias (así como el uso de la imagen en demérito de la Corona) referidos al Rey, su cónyuge, regente o miembro de la regencia o al príncipe heredero. Se trataba, pues, de una regulación muchísimo más correcta, ya que en ese caso sí se estaba protegiendo a un círculo de sujetos que podrían ejercer funciones 
cipe heredero (arts. 490-491 del Código Penal). En segundo lugar, resulta también sorprendente que, a diferencia de cualquier otro órgano, se penalicen las injurias a los citados miembros de la Corona, aun cuando no sean calificadas de graves. Es más, no sólo se sancionan las injurias no graves, sino incluso el uso de la imagen de dichas personas «de cualquier forma que pueda dañar al prestigio de la Corona». De este modo, se dispensa a esta última una protección legal muy superior a la prevista para cualesquiera otros órganos constitucionales.

Tan generosa protección resulta muy discutible en términos constitucionales. Si, como hemos visto, el Tribunal Constitucional avala que la libertad de expresión ha de prevalecer prima facie sobre el derecho al honor en el caso de los órganos públicos, resulta cuestionable que la situación se invierta en el caso de la Corona, donde es evidente que el Código Penal hace prevalecer el honor sobre la libertad de expresión. Al penalizar cualquier injuria —incluso sin ser grave- y también cualquier uso de la imagen que pueda afectar al prestigio de la Corona, se abre camino a un interpretación judicial del Código Penal excesivamente restrictiva para la libertad de expresión. Del mismo modo, conviene no olvidar que la protección penal que se dispensa a los órganos constitucionales trata de protegerlos por la función pública que ejercen, de donde no resulta comprensible que la normativa penal sea tan generosa que abarque no sólo al Rey (que es el único que ejerce funciones constitucionales) sino también a consorte, ascendientes y descendientes, cualesquiera que sean. Puede aducirse que la tutela que se les dispensa deriva de que tales sujetos, en cuanto posibles titulares de derechos sucesorios, pueden ser potenciales jefes del Estado y que, por tanto, protegiéndolos a ellos se tutela a la propia Corona. Es cierto, pero a ello habría que replicar que, en primer lugar, los derechos sucesorios no sólo alcanzan a ascendientes y descendientes, por lo cual, de seguirse el criterio señalado, habría que dispensar protección penal también a parientes colaterales. Por otra parte, en tanto no se ejerza una función pública, la tutela que las normas dispensan a la Corona no debieran tener el mismo alcance, sobre todo si van a suponer limitar derechos fundamentales: no tiene sentido que se proteja al mismo nivel al Rey que a uno de sus nietos, cuyas posibilidades de sucesión, además, pueden ser escasas o incluso nulas (si ha renunciado o ha sido privado de los derechos sucesorios) ${ }^{15}$. En definitiva, las excepciones legales a la libertad de expresión tienen que resultar razonables, y no

constitucionales. Proyecto de L.O. del Código Penal, BOCG. CD, Serie A, n. ${ }^{\circ} 77.1$ (26 de septiembre de 1994). La modificación se produjo al aceptar el Congreso de los Diputados las enmiendas introducidas en el Senado. Enmiendas del Senado mediante mensaje motivado al Proyecto de L.O. del Código Penal, BOCG CD, Serie A, n. ${ }^{0} 77.14$ (13 de noviembre de 1995). El texto aprobado por el Senado: Proyecto de L.O. del Código Penal. Texto aprobado por el Senado, BOCG, Serie II, n. 87 (h), 8 de noviembre de 1995. La enmienda fue introducida en el Senado a petición del GP Popular: Enmienda n. ${ }^{\circ}$ 691, Proyecto de L.O. del Código Penal. Enmiendas, BOCG Senado, Serie II, n. ${ }^{\circ} 87$ (e), 21 de septiembre de 1995, p. 293.

15 Incluso en este último caso, la normativa penal seguiría siendo plenamente aplicable, de modo que el descendiente del Rey privado de derechos sucesorios seguiría siendo considerado parte integrante de la Familia Real y, por tanto, tutelado por la normativa penal al mismo nivel que el propio Monarca. 
lo son cuando la normativa penal resulta tan generosa que la restringe siempre que se dirija hacia cualquier miembro de la Familia Real sin distingos y al margen de la gravedad o no de las expresiones empleadas.

\section{ERROR DE JUICIO}

Como acabamos de ver, las libertades de expresión y de creación artística sólo pueden restringirse por vía legislativa de forma razonable, algo que parece no cumplir nuestro actual Código Penal. Pero, además, cuando el juez aplique esos límites legales, ha de hacerlo de forma proporcionada, de modo que sólo cuando aprecie un flagrante exceso y una clara vulneración del honor puede impedir o sancionar el ejercicio de la capacidad crítica de los ciudadanos. Eso es lo que impone el llamado «efecto recíproco» de los derechos fundamentales derivado de la dimensión objetiva de la que estos disfrutan en un Estado Social de Derecho. Sin embargo, nada de esto parece haberse tenido en cuenta para coartar las libertades constitucionales de los autores de «El Jueves».

En este punto, sin embargo, conviene al menos hacer una distinción entre el auto del juez del Olmo por el que se secuestró la publicación, y la sentencia de la Audiencia Nacional por la que se condenó a los artistas de dicha revista. En el primero, al menos el juez sí mencionó la necesidad de emplear el canon de proporcionalidad, que obliga a que sólo se aplique un límite a un derecho fundamental si esa restricción es idónea, necesaria y proporcionada en sentido estricto (lo que equivale a decir, equilibrada, de modo que la limitación no resulte excesiva para el fin perseguido $)^{16}$. Pero, por más que mencionase el canon de proporcionalidad, su aplicación por el juez Del Olmo no pudo ser más deficiente: como veremos, ni la imagen ni el texto que la acompañaba resultan de una entidad tal que habilite a adoptar, como medida necesaria y equilibrada, nada menos que el secuestro de una publicación, impidiendo que llegue a la ciudadanía. El auto del juez no resiste una aplicación coherente del canon de proporcionalidad.

Así, y en primer lugar, si el objetivo que se pretendía con el secuestro era evitar un daño al honor de la Corona, en teoría puede decirse que el secuestro de la publicación resulta idóneo para tal fin, pero un análisis más detenido demuestra que no es así. El secuestro es, en realidad, una figura anacrónica en el mundo de las nuevas tecnologías: de poco sirve retirar de los puntos de venta físicos la revista en cuestión, si ésta puede circular incluso más eficazmente por internet. Y cerrar la web de la editorial — como hizo también la Audiencia Nacional— tampoco resulta suficiente, porque en cuestión de minutos la imagen supuestamente injuriosa puede

16 Para un análisis detallado de los elementos que integran el canon de proporcionalidad me remito al espléndido trabajo de C. Bernal Pulido, El principio de proporcionalidad y los derechos fundamentales, CEPC, Madrid, 2007 (3. ${ }^{\mathrm{a}}$ ed.), en especial pp. 693-805. 
haberse transmitido a centenares de usuarios quienes, a su vez, la pueden compartir con otros muchos internautas. Pero es que, además, el secuestro no fue idóneo porque, en vez de servir para su objetivo — evitar que se difundiera la portada de la revista-, consiguió justamente lo contrario: un número de «El Jueves» que quizás hubiera pasado más o menos inadvertido, se convirtió, tan pronto fue secuestrado, en una noticia a nivel mundial, y la imagen circuló con una profusión que sin lugar a dudas no habría tenido de no haberse dictado el absurdo auto. Así, en una conversación que pude mantener con el entonces director de la revista «El Jueves», el dibujante A. Monteys, éste me confirmó que por aquel entonces la venta semanal de la revista era de unos 70.000 u 80.000 ejemplares, pero de ese número, tras la notoriedad conferida por su secuestro, las ventas alcanzaron los 110.000 («muy por encima de lo habitual», mencionó expresamente). El secuestro, por su parte, apenas alcanzó a unos cientos de ejemplares, de los cuales ochenta se hallaban en la redacción, que fue registrada al efecto. La famosa portada ha sido objeto de estudio en cursos de derechos fundamentales y ha circulado por las redes, foros, blogs y periódicos digitales con tal profusión que podría decirse que Juan del Olmo fue el mejor publicista que pudo hallar el citado número.

Si el secuestro no fue, pues, idóneo para el objetivo pretendido, menos aún puede decirse que resultase necesario (el posible daño al honor podría verse resarcido a posteriori mediante una sanción) y mucho menos equilibrado: el límite impuesto a la libertad de expresión (silenciándola al impedir que llegase a los ciudadanos) es mucho más severo que el daño que podría haberse ocasionado al bien jurídico protegido (la Corona) de haberse difundido la revista, sobre todo teniendo presente, como tendremos ocasión de analizar, que la portada no resultaba tan ofensiva como apreciaron las instancias judiciales. Así pues, el juicio de proporcionalidad llevado a cabo por el juez del Olmo a través de su auto resultó manifiestamente inadecuado, y no tuvo en cuenta que el secuestro de una publicación es la medida restrictiva más severa que puede adoptarse, y que sólo debería acordarse cuando no hubiese dudas razonables en el juicio de proporcionalidad. Y no era el caso.

Pero si deficiente fue el auto decretando el secuestro de la publicación, más lo fue la sentencia por la que se condenó a los artistas de «El Jueves» por un delito de injurias del artículo 491.1 del Código Penal, y por el uso de imagen dañina para el prestigio de la Corona (art. 491.2 del Código Penal). El hecho de que no se tratase, a juicio del tribunal, de un mero ataque al honor del príncipe heredero, sino de un embate contra la propia Corona, le lleva sin embargo a incurrir en un error de apreciación patente. A su parecer, no tratándose sólo de una violación del honor del príncipe, no procedería una ponderación entre dos derechos fundamentales en conflicto (libertad de expresión de la revista y derecho al honor del príncipe). Antes bien, en este caso, en vez de dos derechos fundamentales que "colisionan» ${ }^{17}$,

17 Dejo a un margen la idea de que, en realidad, no es posible en términos constitucionales hablar de «colisión» de derechos fundamentales. Dos normas del mismo rango supremo no pueden colisionar, ya que de 
nos hallaríamos, a su parecer, con una situación distinta: se trataría de un límite externo que impone el legislador a la libertad de expresión con el objetivo de proteger a un bien jurídico (la Corona). Sin embargo, el argumento yerra ya de mano en considerar que no hay un conflicto entre el derecho al honor y la libertad de expresión: si el juez aplica, como de hecho aplicó, el artículo 491.1 del Código Penal (y no sólo el artículo 491.2), nos hallamos ante un delito de injurias, y éste entraña precisamente ese tipo de conflictos. Y, cuando tal cosa sucede, es imprescindible, según el Tribunal Constitucional, utilizar la técnica de ponderación (por todas, STC 42/1995, FJ 2. ${ }^{\circ}$.

Ahora bien, aun cuando sólo hubiese aplicado el artículo 491.2 del Código Penal (utilización de imágenes de la familia real que desprestigien a la Corona), ello no excusa al juez de tener que emplear el canon de proporcionalidad, ya que éste también es aplicable siempre que una libertad constitucional resulte limitada para proteger un bien jurídico. Y eso es algo que el juez ni tan siquiera menciona en su resolución judicial. Se cuida mucho de afirmar que ningún derecho fundamental es ilimitado - lo cual es cierto — pero se olvida mencionar que tampoco lo es el bien jurídico protegido por la ley (la Corona), de modo que para restringir el derecho fundamental ha de hacerse conforme al canon de proporcionalidad.

¿Y qué implica este canon? Como ya he señalado, supone que el límite que se aplique sea idóneo, necesario y proporcional en sentido estricto (es decir, que haya un equilibrio entre la protección que se dispensa al bien jurídico y la restricción efectiva a la que se sujeta el derecho fundamental). En este sentido, también el artículo 491 del Código Penal exige que se lleve a cabo por el Tribunal una actividad de ponderación, de modo que sólo si se aprecia que la medida limitadora (sanción) es verdaderamente proporcionada para conseguir tutelar el interés público (en este caso la Corona) es admisible que se restrinja la libertad de expresión.

Haciendo caso omiso del canon de proporcionalidad, el tribunal estimó que la imagen de la portada de «El Jueves» era, «objetiva» y «obviamente» injuriosa y, de resultas, dañina para el prestigio de la Corona, con lo cual no cabría alegar en su contra el legítimo ejercicio de un derecho fundamental. Ahora bien, si ponderamos el sacrificio que se exige al derecho fundamental (nada menos que una sanción penal), y el objetivo que se pretende (proteger el prestigio de la Corona), es fácil llegar a una conclusión justamente inversa a la de la sentencia y considerar, con ello, que no ha aplicado en absoluto el canon de proporcionalidad. ¿Cuál es el motivo por el que el juez entendió que se dañaba al prestigio de la Corona? Obviamente, si aplicó el artículo 491 del Código Penal tuvo que ser por considerar que se había utilizado la imagen del entonces príncipe heredero de forma torticera, lo cual conduciría a entender que representar a un miembro de la Corona

lo contrario estaríamos abocados a una antinomia: la preferencia que diésemos a cualquiera de ellos supondría relegar la supremacía del derecho que hemos desplazado. Me remito al respecto a I. Villaverde MenéndeZ. "Esbozo de una teoría general de los derechos fundamentales; Revista Jurídica de Asturias, n, 1998 pp. 33-58. 
en una actividad sexual es, por sí mismo, causante de desprestigio para la institución. Pero, como el juez no se atrevió a tanto, quizás porque sería mantener una idea de la sexualidad más propia del franquismo que del s XXI, pasa de puntillas por ese aspecto, y se centró en que el daño a la Corona derivaba de las palabras que expresa el príncipe en la viñeta. En concreto, el problema radicaría en que, de ellas, y cito expresamente la sentencia: «se tilda al Príncipe, esencialmente, de vago y, por ende, codicioso», lo cual es calificado por el ponente como «indudablemente ultrajante y ofensivo», al punto de no admitir «discusión alguna».

Ahora bien, todo ello no son más que apreciaciones subjetivas del juez que contaminan la resolución adoptada. De la portada lo que se deduce es que el príncipe no había ejercicio nunca un auténtico trabajo, puesto que en realidad no ejercía función constitucional alguna a pesar de cobrar de las arcas del Estado. No se le tilda de vago, por más que se pudiera deducir esa idea. Pero de una idea deducible no puede derivarse una restricción de un derecho fundamental y mucho menos si ésta consiste en una sanción penal, que debiera guiarse por el principio de intervención mínima. Es más, aun en el caso de que expresamente se tildara de vago al príncipe, o cuando fuese absolutamente incuestionable que es lo que se deriva de la portada, se está ejerciendo una crítica admisible de una institución dentro de un sistema democrático, mostrando la irrazonabilidad — para los autores - de sostener con erario público a personas que no ejercen responsabilidad alguna en el Estado.

Resulta alarmante que un juzgado considere que tildar de vago a un miembro de la Corona es evidentemente ofensivo y que ocasiona un descrédito a la Corona tan inadmisible que resulta proporcionado sancionar por ello al autor de tamaña tropelía y secuestrar la publicación en la que se proporciona tan exacerbada afrenta. Si tildar a un órgano del Estado de innecesario, y a su titular ( este caso ni eso, ya que se trataba del príncipe heredero!) de ser un vago se considera merecedor de sanción creo que la única conclusión que podemos extraer, lisa y llanamente, es que en España no existe libertad de expresión.

Que el juez no supo, o más bien no quiso, aplicar el canon de proporcionalidad resulta, pues, evidente. En realidad, «El Jueves» había publicado en numerosas ocasiones portadas en las que cuestionaba el papel del príncipe y de las que también podía deducirse que no desempeñaba trabajo de provecho alguno. Así, por ejemplo en la cubierta del número 957 (28 de septiembre al 3 de octubre de 1995) se veía al heredero de la Corona tumbado en un diván, escuchando música y leyendo, mientras el Monarca le reprochaba que no se marchase de casa. «Es que aquí estoy como un Rey, papi —replicaba el Príncipe-. Por cierto, necesito mil duros». Esta misma crítica alcanzó incluso al propio Monarca. En el número 1065 (22 al 28 de octubre de 1997), tratando la propuesta de reducir la jornada laboral a treinta y cinco horas, aparecía la caricatura del Rey preguntando « ¿iTantas!?». En el número 1338 (15 al 21 de enero de 2003), una caricatura de Juan Carlos I afirmaba preocupado que iba a tener que ponerse a trabajar para llegar a final de mes, y con posterioridad a los hechos aquí comentados, el número 1681 
(12 al 18 de agosto de 2009), bajo el titular «Vacaciones austeras para el Rey» se retrataba a Juan Carlos I tocando la flauta por la calle como un indigente mientras un desconocido transeúnte le increpaba «A ver si trabajas, gandul».

Portadas de este tipo, publicadas incluso después en el recopilatorio «El Jueves y la Monarquía. Tocando los Borbones», fueron consideradas sin embargo por el juez Vázquez Honrubia como un ejemplo de que nuestro sistema constitucional se basa en el principio de intervención mínima, y que sólo en los casos en los que se traspasa el límite de lo tolerable se aplican las pertinentes sanciones ${ }^{18}$. Sin embargo, huelga decir que no hay diferencia alguna entre las portadas referidas y la del citado número, si el problema reside — según su juicio— en la crítica de vago vertida sobre el Príncipe de Asturias.

Pero el desacierto de la sentencia es todavía mayor si se tiene presente que el tribunal parece no tener claro ni tan siquiera el derecho que está limitado. En repetidas ocasiones se refiere a la libertad de información, señalando que ésta ha de ser veraz (como indica el artículo 20.1.d de la Constitución), no quedando demostrada la veracidad de que el príncipe sea una persona vaga. El desatino del argumento es sorprendente. Una sátira, igual que un chiste, difícilmente puede catalogarse como libertad de información y, por lo mismo, resulta imposible que se le exija veracidad. Ya puestos, el juez podría haber dicho que no estaba demostrado que los príncipes españoles utilizaran en su actividad sexual la postura revelada en «El Jueves». La sátira es ejercicio de las libertades de expresión y de creación artística y, obviamente, para ellas no está prevista la exigencia de veracidad que la Constitución impone a la libertad de información.

Un segundo error manifiesto en que incurre la resolución judicial consiste en el argumento que emplea para justificar que «El Jueves» traspasó el límite de lo legalmente permisible. Al parecer del juez, siendo el objetivo de la revista criticar un acto del Gobierno (las ayudas a la natalidad) resultaba innecesario inmiscuir a la Corona, toda vez que este órgano no había intervenido en absoluto en él. Ahora bien, afirmando tal cosa, el juez parece querer convertirse él mismo en el autor de las caricaturas, diciendo exactamente qué se quería criticar en ellas. Bien podría ser que los dibujantes de «El Jueves» lo que quisiesen criticar, como objetivo principal, fuese el inane papel del heredero de la Corona en nuestro sistema constitucional, empleando para ello, como mero artilugio y aprovechando la actualidad política, las subvenciones a la natalidad convocadas por el Gobierno. En todo caso, y aunque no fuese así y llevase razón el juez, la argumentación del tribunal resulta insostenible, ya que un órgano judicial no puede imponer que la libertad de

18 Del citado libro se extrae fácilmente la concepción que «El Jueves» ha mostrado de la Monarquía desde un primer momento, y en la que figura, sin duda, su incapacidad para la vida cotidiana y su naturaleza perezosa; precisamente los rasgos que la sentencia considera que resultan inadmisibles y dignos de sanción. Vid. R. Mogin-Artín, «La monarquía española según la revista El Jueves: Análisis de la antología: Tocando los Borbones», en M.C. Chaput / M. Peloille, Humor y política en el mundo hispánico contemporáneo, Université Paris X-Nanterre, Paris, 2006, p. 117. 
expresión deba ejercerse exactamente de un determinado modo: en este caso, según el juez, para criticar al Gobierno no se podría utilizar a personas ajenas a éste.

\section{LA «INSUMISIÓN»DE «EL JUEVES»}

Por fortuna, ni el secuestro de la revista ni la sanción penal amilanó a los incombustibles artistas de «El Jueves», que en los meses sucesivos siguieron convirtiendo a la Corona en blanco de sus chistes. Las portadas en nada resultaban menos ofensivas que la del número secuestrado, si hemos de seguir las dudosas conclusiones de la Audiencia Nacional. Es posible que sólo el revuelo originado por una medida tan desproporcionada e inimaginable en una democracia saneada y moderna explique el por qué el Fiscal General del Estado se contuvo y decidió no continuar su ofensiva contra «El Jueves».

Y es que la convulsa situación de la Monarquía en los últimos años proporcionó a «El Jueves» sobrante material del que supo sacar partido sin tapujos. De sus portadas siguió desprendiéndose una imagen deconstructiva de la Monarquía española que a menudo hacían irrisoria la cubierta del número secuestrado. Así, por ejemplo, «El Jueves» mostró una imagen de Juan Carlos I como adúltero, a medida que iban circulando noticias sobre sus presuntas infidelidades. ¡Cuán distante quedaba la primera portada en la que «El Jueves» retrató a ambos monarcas, en 1989 como una pareja bien avenida, en la que la separación matrimonial resultaba impensable! ${ }^{19}$ En las antípodas queda la portada publicada casi cinco lustros más tarde, en la que aprovechando la noticia de que Juan Carlos I había participado en una polémica cacería de elefantes en Botsuana, supuestamente con compañía femenina, se retrataba al Rey y la Reina, y tras ésta, un trofeo de elefante en una pared, de tal modo que sus colmillos, situados justo tras la cabeza de la reina Sofía, simulaban unos cuernos. En otra ocasión, se mostraba al Rey portando una enorme pastilla de Viagra telefoneando a Silvio Berlusconi para que le invitase a sus orgías privadas ${ }^{20}$.

La sátira de la vida sexual de la Familia Real —que tan inaceptable y contraria a su honor había considerado la Audiencia Nacional — fue además entreverada por «El Jueves» con otras referencias a situaciones en las que la Monarquía se estaba viendo envuelta. Muy en particular, la imputación de I. Urdangarín por el denominado «caso Noos». Así, ante la noticia de que el yerno de los reyes no los acompañaría a las tradicionales vacaciones mallorquinas —en un intento de desvincular al Monarca del duque de Palma_- «El Jueves» publicó una portada en la que Juan Carlos I recibía un sartenazo de su cónyuge al comunicarle la posibilidad de que, en

19 En efecto, en el n. ${ }^{\circ} 634$ (julio de 1989) bajo el titular «Los famosos se separan» se retrataba a los reyes leyendo en su dormitorio. La reina, con la revista «Hola» en sus manos, le decía a Juan Carlos I: «Al final, sólo quedaremos tú y yo».

20 «El Jueves», n. ${ }^{\circ} 1822$ (abril de 2012) y «El Jueves», n. ${ }^{\circ} 1673$ (junio de 2009). 
ausencia de Urdangarín, una amiga alemana del Rey ocupase su lugar. En otra ocasión, se caricaturizaba al yerno del Rey ofreciendo al juez un vídeo de Juan Carlos I con Bárbara Rey, como contrapartida para evitar su procesamiento ${ }^{21}$.

Bien es cierto que a las referidas portadas acusando al Rey de adúltero carecían de referencias sexuales explícitas, a diferencia de lo que sucedía con el número secuestrado. Pero hasta esa situación se superó. Por una parte, con referencias textuales, como en la portada en la que se retrataba a un decrépito Juan Carlos I acompañado de su supuesta amante quien decía «Sólo nos une una entrañable amistad», a lo que la portada añadía: «O sea: al Rey ya no se le levanta». Pero tampoco faltó una imagen del Rey todavía más explícita que la del número secuestrado: aquella en la que se mostraba a un ujier sosteniendo los genitales de Juan Carlos I. Igual de explícita era la portada que retrató a Letizia — todavía princesa pero, no se olvide, amparada incluso en su condición de tal por el Código Penal- como si fuese una activista de FEMEN, con el torso desnudo en el que se leía «Fuck the Royals», en alusión a su reconocida preferencia por el republicanismo ${ }^{22}$.

No deteniéndose aquí, tras la condena de I. Urdangarín, y la absolución penal de la infanta Cristina, la revista prácticamente calcó la portada del número secuestrado, retratando a los citados sujetos en la misma posición sexual, con el chiste de que la infanta sólo acudiría a la cárcel en los «bis a bis» con su cónyuge. Número que no gustó, obviamente a la infanta, que amenazó con emprender acciones legales, seguramente envalentonada por la insensata sentencia favorable a la Corona que aquí hemos analizado. Aun así, los editores de «El Jueves» publicaron justo en el número siguiente una caricatura idéntica, esta vez con R. Rato y la infanta Elena como protagonistas. El hecho de que no se adoptase prisión provisional contra el primero, a pesar de su condena por el uso de las «tarjetas black», dio lugar al chiste de la portada, insinuando que el exministro se había casado con la infanta Elena, y de ahí que su trato procesal resultase tan beneficioso ${ }^{23}$.

Así pues, las imágenes y los chistes de connotaciones sexuales referidos a la Corona y a la familia real siguieron siendo un tema recurrente en «El Jueves». Y aun así, resultan extremadamente pacatos si hemos de compararlos con mofas a las que se sometía a Isabel II en el libro «Los Borbones en pelota», elaborado por Gustavo Adolfo Becquer y que, de tan osado, no pudo llegar a circular libremente. En todo caso, no fueron estos los únicos temas en los que «El Jueves» satirizó a la Familia Real. La ya referida imputación de I. Urdangarín y de la infanta Cristina también halló acomodo en algunas llamativas portadas de la revista. ¿Puede decirse que, en este caso, el hecho de que existiese un proceso penal justificaba más las críticas? Si siguiésemos el incorrecto parecer del juez Vázquez Honrubia, la respuesta tendría que ser negativa. En primer lugar, porque, si los chistes gráficos fuesen, como él

21 «El Jueves», n. ${ }^{\circ} 1837$ (agosto de 2012) y «El Jueves», n. ${ }^{\circ} 1824$ (mayo de 2012).

22 «El Jueves», n. 1868 (marzo de 2013), «El Jueves», n. ${ }^{\circ} 1758$ (febrero de 2011) y «El Jueves», n. ${ }^{\circ} 1892$ (agosto de 2013).

23 «El Jueves», n. ${ }^{\circ} 2074$ (febrero de 2017) y «El Jueves», n. 2075 (marzo de 2017). 
considera, «libertad de información» (y no libertad de expresión) muchas portadas podrían atentar contra la presunción de inocencia y de resultas podrían «menoscabar» el prestigio de la Corona. Ese sería el caso, por ejemplo, de la portada conmemorando el día de San Valentín, en el que se retrataba a Urdangarín y Cristina de Borbón dentro de un corazón y portando maletines rebosantes de dinero bajo la leyenda «Feliz San Maletín». Pero, en segundo lugar, menos aceptable tendría que ser —bajo los parámetros de la sentencia- otra portada en la que, haciéndose eco del argumento de la infanta para evitar la imputación de su desconocimiento de los negocios de su esposo, «El Jueves» destacaba en letras que cubrían casi toda la página «Única conclusión posible: la infanta Cristina es tonta» ${ }^{24}$. Si tenemos en cuenta que el Tribunal Constitucional ha señalado que no hay un derecho al insulto o, lo que es lo mismo, que las palabras vejatorias no pueden ampararse en el ejercicio legítimo de la libertad de expresión (STC 172/1990, FJ 3.`), sería más posible en este caso, que en el del número secuestrado, que cupiese algún tipo de afectación al derecho al honor.

Otras portadas de «El Jueves» podrían mostrar una imagen del Rey como sujeto infractor de las normas, algo desde luego más grave que la crítica de «vago» expuesta en el número 1573 sometido a la Audiencia Nacional. Así, por ejemplo, podría colegirse la idea de que el Rey no está al corriente de sus obligaciones tributarias en la cubierta de «El Jueves» en la que se retrataba a Juan Carlos I quemando facturas bajo el titular «Hacienda investiga a famosos» ${ }^{25}$. Más lejos llegaba incluso una portada de 2013 en la que, trayendo a colación una vez más el «caso Noos», aparecía Juan Carlos I desnudo en la cama, junto con una alegoría de la justicia cuyos pechos manosea el Rey, mientras le dice: «Y ahora me desimputas a la niña, ¿eh, guarrilla?»; todo ello bajo el titular: «Corinna ya es pasado. Ahora el Rey se folla a la Justicia». La portada lo tiene todo para incurrir en responsabilidad penal si se siguiese el riguroso criterio de la Audiencia Nacional: existe un componente sexual manifiesto, junto con una acusación clara de que la Casa Real interfiere en el correcto funcionamiento del poder judicial a fin de obtener un trato beneficioso ${ }^{26}$.

De todo ello se desprende que «El Jueves» ha publicado, tras su injusta persecución, portadas tanto o más «ofensivas» para la Corona, según el estricto criterio utilizado por la Audiencia Nacional. Por fortuna para los lectores, ninguno de esos números acabó tan mal como el de julio de 2007. La explicación no debe buscarse en que se trate de críticas menos lacerantes (como he dicho, no es así) o que en este caso sí se han ajustado a la libertad de expresión (en realidad, también

24 «El Jueves», n. ${ }^{\circ} 1916$ (febrero de 2014) y «El Jueves», n. ${ }^{\circ} 1809$ (enero de 2012).

25 «El Jueves», n. ${ }^{\circ} 1929$ (mayo 2014).

26 Recientes portadas han sido igual de críticas con la justicia española, sobre todo a raiz dek juicio en el Tribunal Supremo contra los líderes del "Procés" (n 2177, febrero de 2019). Portadas que responden al indisimulado posicionamiento de la revista a favor del secesenismo y sus líderes. De hecho, en un artículo de octubre de 2018, la revista acusó a la Policía Nacional que había intervenido el 1-O de consumir cocaína. Lo que dio lugar a la apertura de nuevas diligenias penales contra la publicación por injurios, en el Juzgado de Instrucción n 20 de Barcelona. 
lo hicieron en el número secuestrado, como he tratado de demostrar). El motivo seguramente sea otro menos jurídico: el secuestro del número 1573 y de la pena impuesta a M. Fontdevila y G. Torres levantó un lógico revuelo mediático y una respuesta por parte de la opinión pública que quizás desanimó a la Fiscalía General del Estado a repetir su ridícula persecución a «El Jueves».

Parecía, pues, que la «sanción ejemplarizante» no había cumplido su propósito, sino todo lo contrario, de modo que la libertad de expresión y creación artística habrían salido reforzadas a la postre de tan injusto lance. Pero no fue así totalmente...

\section{DAÑOS COLATERALES}

Los desafortunados auto y sentencia de la Audiencia Nacional, apoyados en la interpretación más restrictiva de los derechos fundamentales posible en un Código Penal que en este caso ha optado por la «intervención máxima» para proteger a la Corona, tuvieron un alcance que va más allá de la sanción pecuniaria a los artistas de «El Jueves» y del secuestro del número 1573 de la revista. Marcó un peligroso precedente —que seguramente hubiera podido corregirse si se hubiese recurrido en amparo la sentencia - y pudo contribuir a la «censura corporativa» que la editorial RBA impuso siete años más tarde a la portada del número 1932 (4-10 de junio de 2014). Esta portada se refería a la abdicación del rey Juan Carlos I, y en ella, el (reincidente) caricaturista M. Fontdevila retrataba a aquel colocando con unos alicates una corona llena de heces sobre la cabeza de Felipe VI.

Posiblemente el miedo a un nuevo secuestro de la publicación, o el mero interés económico de no causar ofensa alguna a la Casa Real, hizo que RBA (dueña de la revista desde 2006) destruyera sesenta mil ejemplares antes de que vieran la luz, retrasando con ello la salida de «El Jueves». El nuevo ejemplar ya no tenía a los monarcas saliente y entrante como protagonistas, sino al líder del partido político «Podemos», P. Iglesias. De resultas de esta decisión editorial, varios miembros de la revista, como el propio M. Fontdevila, junto con A. Monteys, B. Vergara e I. Rosa, entre otros, abandonaron la publicación.

Y es que, cuando el Estado o la sociedad tratan de coartar la libertad de expresión, al daño emergente que con su conducta causan, se suma el daño colateral que pueden traer consigo, la autocensura, a veces más severa que el propio control por parte de las autoridades.

Conviene recordar esta circunstancia, ya que el excesivo celo en la tutela de derechos colindantes con la libertad de expresión pueden acabar convirtiéndola en una libertad autocercenada. De poco sirve que la Constitución prohíba la censura si el contexto social, normativo y judicial acaba propiciando situaciones de autocensura.

En el siglo xIX el derecho al honor y a la intimidad, concebidos como esferas derivadas del sacrosanto individuo eran los que actuaban como principales 
restricciones para el ejercicio de la libertad de expresión. La irrupción de la democracia alteró esta escala de valores, y la necesidad de construir una opinión pública libre permitió injerencias en las esferas privativas del individuo, en especial si éste era autoridad o persona de relevancia pública. Sin embargo, a día de hoy un nuevo derecho, íntimamente ligado a la democracia, como es la igualdad, actúa en ocasiones como cortapisa de la libertad de expresión. Puesto que la Constitución no sólo proclama la igualdad formal «en» la ley y «ante» la ley (art. 14), sino también la igualdad real y efectiva (art. 9.2) que permite incluso la adopción de medidas de discriminación positiva, hay quien entiende que cualquier tipo de expresión que falte al más estricto y escrupuloso equilibrio igualitario debe ser inmediatamente sancionado.

Se pasa con ello por alto que la igualdad real y efectiva es una imposición a los poderes públicos, no a los particulares, más allá por supuesto de lo que especifiquen las concretas normas de desarrollo constitucional. Por tanto, no es exigible a los particulares que sus expresiones contengan un exquisito tratamiento paritario. Ciertas expresiones serán mezquinas, sexistas, racistas y repugnantes, pero tendremos que tolerarlas porque no por ello serán antijurídicas. Y, como dijo Orwell en la que sigue siendo una de las mejores definiciones de la libertad de expresión, ésta consiste en tener que oír aquello que no nos gusta.

Casos como el de «El Jueves» deben hacernos reflexionar que los prejuicios y preferencias particulares —incluso si proceden de un juez-son uno de los principales peligros con los que puede toparse la libertad de expresión. Sobre todo cuando queremos imponerlos.

$$
* * *
$$

TITLE: Freedom of speech and crown protection: the "El jueves" Case

AвSTRACT: In 2007 the Spanish satirical journal "El Jueves" was under judicial confiscation and two of its authors were prosecuted for criminal offense against the Crown's honor. Both judicial resolutions subjected the freedom to expression to exceptional restrictions and moved the publishers to further self-censure. Nevertheless, these restrictions dealt with an inadequate protection to Crown honor in Spanish Criminal Code, and with a wrong use of the proportional clause by the Audiencia Nacional.

RESUMEN: En 2007, la revista satírica «El Jueves» sufrió un secuestro judicial, y dos de sus dibujantes resultaron condenados por un delito contra el honor de la Corona. Ambas resoluciones judiciales sometieron la libertad de expresión a unas restricciones excepcionales, y dieron lugar a que los propios editores optaran con posterioridad a medidas de autocensura. Sin embargo, tales restricciones fueron fruto de una inadecuada protección del honor de la Corona en el Código Penal, y de uso erróneo de la cláusula de proporcionalidad por parte de la Audiencia Nacional.

KEY WORDS: freedom of expression, judicial confiscation, Crown, right to honor, criminal code, proportional clause.

Palabras clave: libertad de expresión, secuestro judicial, Corona, derecho al honor, Código Penal, cláusula de proporcionalidad.

FECHA DE RECEPCIÓN: 16.06.2018

FECHA DE ACEPTACIÓN: 05.02.2019 
